\title{
Pilot Scale Mill Characterization and Evaluation of Rice Bran Oil Concentration of Jazzman Rice
}

\author{
Rebecca Schramm¹, Grant Gonzalez², Nicole Walker², Marybeth Lima ${ }^{2 *}$ \\ ${ }^{1}$ Engineering Science, Franklin Pierce University, Portsmouth, NH, USA \\ ${ }^{2}$ Department of Biological and Agricultural Engineering, Louisiana State University Agricultural Center, Baton \\ Rouge, LA, USA \\ Email: ${ }^{*}$ mlima1@|su.edu
}

Received 25 June 2015; accepted 3 August 2015; published 6 August 2015

Copyright (C) 2015 by authors and Scientific Research Publishing Inc.

This work is licensed under the Creative Commons Attribution International License (CC BY). http://creativecommons.org/licenses/by/4.0/

(c) (i) Open Access

\section{Abstract}

The demand for aromatic rice has increased in the United States during the last two decades. Jazzman, the first US-bred jasmine-type rice variety, was released by the Louisiana State University (LSU) AgCenter Rice Research Station in 2008 to compete for a market share of jasmine-type rice. Jazzman, a long grain aromatic rice variety, was developed from a cross between Ahrent and an unreleased aromatic Chinese rice line 96a-8. In pre-release field tests and laboratory scale evaluation, Jazzman rice yield and milling quality compared favorably with two high-yielding and good-milling non-aromatic long grain varieties, Cypress and Cheniere. Pilot scale evaluation of Jazzman for milling quality supported laboratory scale evaluation while providing additional data for milling optimization. Pilot scale milling uses larger rice samples than laboratory scale testing and employs a continuous process instead of the batch process used at laboratory scale. As a result, pilot scale milling offers more comprehensive information regarding the milling yield and quality of rice varieties as they are considered for industrial scale release. Another consideration for new rice varieties involves their potential for value-added processing, in which waste streams during processing can be used to create valuable products. The oil from rice bran is one such product. The objective of this study was to use pilot scale milling to determine the potential of Jazzman for industrial scale release, including its potential for value-added processing. Results showed that bran was easily removed during milling; the head rice recovery ranged from $66 \%$ to $74 \%$ as a function of milling flow rate. Water polishing had little effect on head rice recovery, but improved the final degree of milling (DOM) to a commercially acceptable level of 87 - 90 . Additionally, rice bran oil concentration decreased as pilot scale flow rate increased, indicating that oil was concentrated in the outer bran layer of Jazzman. Pilot scale milling shows that Jazzman is a high-yielding and goodmilling aromatic long grain rice variety.

${ }^{*}$ Corresponding author.

How to cite this paper: Schramm, R., Gonzalez, G., Walker, N. and Lima, M. (2015) Pilot Scale Mill Characterization and Evaluation of Rice Bran Oil Concentration of Jazzman Rice. American Journal of Plant Sciences, 6, $1885-1892$. 


\section{Keywords}

\section{Jasmine, Milling, Pilot Scale, Rice Bran Oil, Extraction}

\section{Introduction}

The US demand for jasmine-type rice has increased over the last two decades. Most of this demand is currently met with imports [1]. In 1992, the LSU AgCenter Rice Research Station Specialty Rice Breeding Program was formed to develop rice varieties suitable for growing in Louisiana with the goal of competing commercially in the United States. There has been limited market success to date with jasmine varieties grown in the United States. Jasmine 85, an aromatic rice variety developed by the International Rice Research Institute, was grown on limited acreage in the southern United States [2]. Jasmine 85 failed to meet consumer expectations due to gray coloring in the kernels and inferior aroma [3]. Jazzman (Oryza sativa L.), the first US-bred jasmine-type rice, was released by the LSU AgCenter Rice Research Station in December 2008 [1].

Jazzman is a long grain aromatic rice variety that was developed from a cross between an Arkansas variety, Ahrent, and an unreleased aromatic Chinese rice line 96a-8. Jazzman averaged $7803 \mathrm{~kg} \cdot \mathrm{ha}^{-1}$ in yield trials over five years in five states, comparing satisfactorily with two non-aromatic long grain varieties, Cypress and Cheniere [3], which had mean yield values of 7841 and $8903 \mathrm{~kg} \cdot \mathrm{ha}^{-1}$, respectively [4]. Jazzman exhibited commercially viable milling yield and quality in early laboratory scale screening tests [2]. Jazzman head rice recovery was $63.6 \%$, which was within the range of values for Cheniere and Cypress at $63.1 \%$ and $64.3 \%$, respectively [4]. Jazzman compares to Cypress in plant height and days to maturity, while being less susceptible to blast and sheath blight than Cheniere. Initial release documentation for Cypress, Cheniere, and Jazzman did not include values for degree of milling (DOM), whiteness, and transparency. Because these values are important quality indicators, they are measured at the pilot scale.

Laboratory scale evaluation has traditionally provided milling quality information on new rice variety releases, and in most cases, successfully predicted industrial scale performance [5]. The standard laboratory mill used in testing, a McGill mill, operates in batch format by removing bran from shelled rice in one chamber. Milling studies at laboratory scale use samples of 125 to $150 \mathrm{~g}$ to evaluate milling performance. Commercial mills operate in a continuous process using three or four milling units referred to as milling breaks. Each break uses abrasion or friction to remove the bran layer [6] and the typical minimum amount of rice processed is $900 \mathrm{~kg}$.

To provide a closer analog to commercial mills, the LSU AgCenter pilot scale mill was used to measure the milling performance of Jazzman. The LSU AgCenter pilot scale mill operates in a continuous process and requires a larger sample (at least $11.5 \mathrm{~kg}$ ) than laboratory scale testing; this approach provides a similar operating process to the industrial scale and the larger sample size is thought to minimize errors due to orders of magnitude in scale up [5].

Milling quality assessment for rice varieties includes quantification of grain appearance and measurement of milling yield and head rice recovery. Grain appearance was measured using standard industry values of whiteness, transparency, and degree of milling (DOM) [7], which related to the amount of bran removed and the visual appearance of rice kernels. Millers use both milling yield and head rice recovery to evaluate overall rice kernel quality. Milling yield was quantified as the ratio of the weight of unbroken milled rice to the total weight of milled rice and head rice recovery was quantified as the ratio of whole kernel milled rice to the weight of rough rice processed [8].

Despite its advantages to traditional laboratory scale milling, pilot scale milling has not been widely used in the development of new rice varieties. Thus, this study adds to the dearth of literature on this novel milling method. Hua et al. [5] milled Cocodrie at pilot scale and examined processing parameters of milling recovery, wholeness, transparency, whiteness, and DOM as a function of roll gap size (husking), feed volume or flow rate (milling), and water polishing velocity (polishing). Optimal mill settings for Cocodrie at pilot scale were determined and utilized to improve milling quality at the industrial scale [5].

Pilot scale milling can also be used to assess the potential of a rice variety for value-added processing, a method in which waste streams produced during processing can be used to create other valuable products. Rice bran is a primary source of interest for value-added processing in rice milling. As world energy consumption in- 
creases, the United States Department of Energy (DOE) plans to replace fossil fuels with biofuels produced from biomass. Rice bran conforms to the DOE's definition of biomass, which includes agricultural and forest residue, municipal solid waste, and energy crops [9].

Oil extracted from rice bran has been converted to biodiesel by a variety of methods including basic [10] and acidic catalyzation [11], lipase-catalyzation [12], and transesterification by tin compounds [13]. With oil concentration in rice bran ranging from $15 \%$ to $25 \%$ [14], the identification of high oil content rice varieties improves the potential for the success of a new rice variety. Previous research has shown that by fractionating the rice bran layer, high oil concentration fractions can be obtained that further boost the commercial viability of rice bran and rice bran oil [15] [16]. By measuring the oil in the bran layer as a function of milling flow rate (low, medium, and high bran removal), it is possible to determine whether fractions of the bran layer have different oil concentrations, and if so, which milling conditions produce bran optimal for the production of biodiesel.

This study was motivated by collaboration between the Rice Research Station and the authors to provide additional milling information on this new rice variety and to provide pilot scale data for this rice variety for researchers who wish to further investigate this novel processing scale. Additionally, the byproduct of this rice variety could be used to produce biodiesel fuel. The objectives of this study were to:

1) Measure the percent of bran removed from Jazzman as a function of pilot scale milling flow rate;

2) Determine head rice recovery, whiteness, transparency, and DOM of Jazzman at these flow rates;

3) Identify the optimal range of pilot scale mill settings for Jazzman;

4) Determine the rice bran oil concentration as a function of pilot scale mill setting.

\section{Materials and Methods}

Jazzman rice was milled at the pilot scale at low, medium, and high flow rates in triplicate, and milling and quality parameters were determined. Rice bran obtained from these experiments was extracted and oil concentration was measured. The standard methods for experiments and analysis are detailed in the following paragraphs.

\subsection{Sample Preparation}

Jazzman provided by the LSU AgCenter Rice Research Station was stored in a freezer at $0^{\circ} \mathrm{C}$ until the day before processing. A period of 24 hours allowed the rice to achieve ambient temperature at $29^{\circ} \mathrm{C}$ before milling.

\subsection{Processing}

Rice was processed using a pilot scale milling plant (Satake Engineering Co. Tokyo, Japan) which operates in a continuous process and consists of a husker (model GPS300A), a mill (model VAF10AM), a wet polisher (model BA3AW), and a color sorter (model GS3AA). Samples of $11.5 \mathrm{~kg}$ were processed in triplicate at three selected pilot scale operational settings corresponding to low, medium, and high flow rates of milling. Milled rice refers to rice that has been processed with the milling or whitening unit (model VAF10AM), while polished rice refers to rice that has been further processed through the water polisher (model BA3AW).

\subsection{Flow Rate Determination}

The pilot scale mill has flow settings ranging from 1 to 9 . These settings correspond to mass flow rates that are specific for a given rice variety, and range from approximately $50 \mathrm{~kg} \cdot \mathrm{h}^{-1}$ at flow setting 1 to approximately 850 $\mathrm{kg} \cdot \mathrm{h}^{-1}$ at flow setting 9 . These values are approximate because different rice varieties will have different mass flow rates as a function of how difficult the bran is to remove from the kernel. Thus, the flow rate of rice of a particular rice variety is determined for a specific flow setting by measuring the mass of a given volume of rice $(11.5 \mathrm{~kg})$ that leaves the whitening unit divided by the time it takes for that rice to pass through the chamber. From triplicate measurements, mean flow rates were reported in $\mathrm{kg} \cdot \mathrm{h}^{-1}$ for pilot scale mill settings of 3,5 , and 9 . The actual mean flow rates in $\mathrm{kg} \cdot \mathrm{h}^{-1}$ for the three settings used were 124,344 , and 806 , respectively. The selected settings corresponded to the low, medium, and high flow rates, respectively, determined in previous optimization studies of rice milling, which showed that flow rate setting was the controlling factor in pilot scale mil- 
ling [5].Flow rates increase between successive mill settings used in testing, approximately doubling in value.

\subsection{Bran Removal and Milling Quality}

Nine rough rice samples of $11.5 \mathrm{~kg}$ were shelled, milled, and their weights measured after each process step. Shelled rice samples of $125 \mathrm{~g}$ and $2.5 \mathrm{~kg}$ were collected from each replicate processed. The $2.5 \mathrm{~kg}$ sample was further processed through the water polisher and reweighed. From the polished rice, samples of $125 \mathrm{~g}$ were collected. A shaker table (Model 61-115-60, Grainman Machinery Co., Miami, Florida) using sorter trays of ASTM size 10 (top) and 12 (bottom) removed broken kernels of rice from the $125 \mathrm{~g}$ milled and polished rice samples. Head rice recovery was determined as a weight percent of unbroken kernels to the weight of the rough rice sample processed for milled and polished rice [8]. The amount of bran removed for each mill setting was determined from the difference between the weights of shelled and milled rice. Bran removal was reported as a percentage based on the weight ratio of bran removed to the weight of shelled rice processed. During milling, whiteness, transparency, and DOM were measured for milled and polished rice samples in triplicate with a Satake milling meter (model MM-1D, Tokyo, Japan) [5]; the mean of the three readings was reported. Based on milling quality results, optimal operational conditions were determined.

\subsection{Hexane Extraction}

Rice bran samples were collected from each replicate and rice bran oil was extracted using the method detailed in Proctor et al. [17]. A brief description of this method is as follows: one gram of rice bran was combined with 10 milliliters of hexane and stirred for 10 minutes. Samples were centrifuged, decanted, and the solvent was evaporated. Oil concentration was determined from weight measurements and reported as a weight fraction of oil recovered to bran processed for hexane extractions. Bran concentration for each replicated was calculated by subtracting the oil content in the milled rice sample from the oil content of the shelled rice sample.

\subsection{Statistical Analysis}

Experiments were completely randomized. Three replicates were performed for each milling flow rate combination. Statistical analysis at a 5\% significance level was performed with ANOVA and Tukey mean comparisons using XLSTAT-Pro 2009 [18].

\section{Results and Discussion}

\subsection{Rice Milling and Quality}

Table 1 shows milling yield and quality results for milled and polished rice as a function of flow rate. The percent of bran removed, DOM, and whiteness values increase with increasing flow rates for milled rice. No difference in the mean amount of bran removed was observed between successive mill settings for milled rice, indicating that bran is easily removed from the kernel for this variety. Bran removed ranged from $12 \%$ to $14 \%$ for milled rice, and from $14 \%$ to $16 \%$ for polished rice. Water polishing removed $3.4 \%, 1.0 \%$, and $0.6 \%$ of bran at mill setting rates of 124, 344, and $806 \mathrm{~kg} \cdot \mathrm{h}^{-1}$, respectively. The Standards Committee of the American Association of Cereal Chemists recommended a $12 \%$ reduction in weight between shelled rice and milled rice samples for a well-milled sample [19]. Results indicate that minimal milling is necessary to remove the recommended $12 \%$.

Jazzman milling yield and head rice recovery compare well to non-aromatic and aromatic long grain rice varieties. Head rice recovery decreased with increasing flow rate for milled and polished Jazzman due to the increase in friction milling at higher flow rates. No significant difference existed between mean values for milled and polished head rice recovery, which were $70.9 \%$ and $70.8 \%$ respectively. Laboratory scale evaluation found a head rice recovery of $63.6 \%$. Jazzman head rice recovery compares well with head rice recovery values of Cypress and Cheniere, which are considered good milling varieties of rice with head rice recovery values of $64.3 \%$ and $63.4 \%$, respectively [2] [4].

The mean pilot scale head rice recovery value of $71 \%$ was higher than the laboratory measurement of $63.6 \%$. This is likely due to the batch lab versus continuous pilot scale differences in processing. Laboratory scale mills operate in a batch format with all milling accomplished in one step. Pilot scale mills operate by removing bran 
Table 1. Milling yield and quality measurements as a function of pilot scale milling flow rate.

\begin{tabular}{ccccc}
\hline $\begin{array}{c}\text { Rice milling and quality } \\
\text { measurements }\end{array}$ & Quality of rice & 124 & Milling flow rate, $\mathrm{kgh}^{-1}$ \\
\cline { 2 - 4 } Bran removed (\%) & Milled rice & $12.2 \pm 2.0 \mathrm{a}$ & 344 & 806 \\
\hline & Polished rice & $3.4 \pm 1.0 \mathrm{a}$ & $1.0 \pm 0.3 \mathrm{~b}$ & $0.6 \pm 0.5 \mathrm{~b}$ \\
Head rice recovery (\%) & Milled rice & $74 \pm 0.5 \mathrm{a}$ & $72 \pm 1.4 \mathrm{a}$ & $66 \pm 1.2 \mathrm{~b}$ \\
& Polished rice & $73 \pm 1.6 \mathrm{a}$ & $70 \pm 3.3 \mathrm{a}$ & $69 \pm 0.0 \mathrm{~b}$ \\
Megree of milling (DOM) & Milled rice & $73 \pm 4.9 \mathrm{a}^{*}$ & $80 \pm 3.0 \mathrm{a}$ & $86 \pm 2.1 \mathrm{~b}$ \\
Polished rice & $87 \pm 7.8 \mathrm{a}^{*}$ & $88 \pm 5.3 \mathrm{a}$ & $90 \pm 4.0 \mathrm{a}$ \\
Mransparency & Milled rice & $33.5 \pm 0.8 \mathrm{a}^{*}$ & $35.6 \pm 0.7 \mathrm{a}$ & $37.0 \pm 0.4 \mathrm{~b}$ \\
& Polished rice & $37.4 \pm 1.5 \mathrm{a}^{*}$ & $37.1 \pm 1.1 \mathrm{a}$ & $38.0 \pm 1.1 \mathrm{a}$ \\
& Milled rice & $3.7 \pm 0.2 \mathrm{a}^{*}$ & $3.5 \pm 0.1 \mathrm{a}$ & $3.4 \pm 0.1 \mathrm{~b}$ \\
\hline
\end{tabular}

Values \pm 1 standard deviation reported. The same letter across a row indicates no statistical difference; ${ }^{*}$ indicates two data points.

in a series of steps. Chen et al. [6] found that more rice was broken in a single break system than a multiple break system for any DOM level. They observed progressively decreasing head rice recovery with increasing DOM for the single break system, but for the multiple-break mill, most of the broken kernels were seen early in milling [6]. This result is significant because if laboratory scale tests of a prospective rice variety are "borderline", $(\sim 60 \%$ or less) producers may abandon the variety, when pilot scale milling may prove it commercially viable.

Mean milling yield is $90 \%$ for Jazzman, which compares well with Cypress, Cheniere, and Cocodrie yields of $91 \%, 87 \%$, and $88 \%$, respectively [4]. Islam et al. [20] studied milling quality of two Bangladeshi long grain aromatic varieties using $30 \mathrm{~kg}$ rough rice samples at the pilot scale. Milling yields were $90.4 \%$ and $84.1 \%$ with head rice recovery measured as $60.2 \%$ and $60.1 \%$ [20]. Jazzman's milling yield of $90 \%$ was in the range for the two Bangladeshi aromatic varieties, and Jazzman's head rice recovery of $71 \%$ exceeded the head rice recoveries of the Bangladeshi varieties. Yield data indicate that Jazzman is a commercially viable rice variety.

Measurements for DOM, whiteness, and transparency indicate the visual quality of rice kernels. There is a lack of data regarding published values of whiteness and transparency [21] [22] because DOM is typically used as the major indicator to assess the quality of milled rice. A laboratory scale study of medium grain rice determined mean whiteness values of 41.5 to 45.7 , dependent on rice variety and condition [23]. The few points of difference in whiteness values observed are accounted for by different rice varieties, differences in rough rice quality, or the difference in milling scale. Our study found whiteness values between 37.1 and 38.0 for polished rice, which are significantly lower than those found in literature. These values indicate that the kernel is not as white as typical rice varieties; this issue was problematic with a previously released US-grown jasmine rice variety [3]. DOM and whiteness values increased with flow rate; transparency values exhibit little change with flow rate. Tukey mean comparisons found some significant differences between milled and polished rice values for DOM and whiteness. The polished rice DOM of all flow rates $(87-90)$ falls within the expected commercial DOM ranges from 85 to 95 [24]. Transparency values of polished rice ranged from 3.2 to 3.7 percent and exhibited no significant difference as a function of flow rate.

Figure 1 presents milled rice DOM and head rice recovery as a function of milling flow rate. The final decision of operational flow rate affects the head rice recovery and kernel appearance. At laboratory scale, head rice recovery and DOM exist in an inverse relationship [24]. Our findings at pilot scale display the same general pattern of higher DOM with lower head rice recovery. Increasing flow rate increases the amount of bran removed and the number of broken kernels, establishing an inverse relationship which must be considered when selecting an operational range for flow rate.

For milled rice, Jazzman exhibited minimal differences in head rice recovery and DOM among flow rates. 




Figure 1. Yield and quality parameters as a function of flow rate; means \pm 1 standard deviation reported.

Head rice recovery for a flow rate of $806 \mathrm{~kg} \cdot \mathrm{h}^{-1}$ was lower than for flow rates of 124 and $344 \mathrm{~kg} \cdot \mathrm{h}^{-1}$. Head rice recovery values at flow rates of 124 and $344 \mathrm{~kg} \cdot \mathrm{h}^{-1}$ exhibited no statistical difference. Milled rice DOM values exhibited no difference between 344 and $806 \mathrm{~kg} \cdot \mathrm{h}^{-1}$. The data indicate that low flow rate milling optimizes head rice recovery and DOM. Milled rice at $124 \mathrm{~kg} / \mathrm{hr}$ has a head rice recovery of 74 and a DOM of 73 . The head rice recovery exceeded values for Cypress and Cheniere with head rice recoveries of 64 and 63, respectively. The DOM value for milled rice fails to meet industry expectations for DOM of 85 to 95 [24]. However, after water polishing, which is also employed at industrial scale, the DOM was 87 , meeting commercial expectations. DOM increases as milling flow rate increases, and a higher DOM may be warranted with respect to the lower whiteness values.

Pilot scale milling results suggest that the Jazzman rice variety can be scaled up to industrial levels with acceptable kernel quality and milling yields that meet or exceed that of current commercial varieties. The product obtained would be able to compete well with other long grain aromatic rice varieties for the niche aromatic rice market in the United States. More broadly, this study illustrates the impact of pilot scale milling in new rice variety development. Milling at pilot scale is improved over milling at lab scale as it more closely mirrors industrial scale milling. This study showed that for this particular variety, the mean head rice recovery $(71 \%)$ was significantly higher than the value obtained at laboratory scale (63\%). Such differences can "make or break" a prospective rice variety, and conditions that more closely model the actual industrial scale process provide millers with a better data set from which to judge commercial viability. Industrial scale millers can use pilot scale milling data, such as the data presented in this paper, to determine initial mill settings for a new rice variety and can fine tune milling by adjusting their milling ratios to maximize milling and/or quality parameters. Researchers focused on rice variety development can use pilot scale milling data to drive rice variety development and/or improvement. For example, the LSU AgCenter rice research station released Jazzman 2 [21], which exhibited improved whiteness during milling and is now being grown in substantial acreage in the state.

\subsection{Rice Bran Oil Extraction}

Figure 2 presents the oil concentration obtained from rice bran as a function of milling flow rate. Oil concentration decreased as pilot scale mill setting increased, indicating that the highest concentration of rice bran oil is obtained in the outer bran layer. The oil concentration of bran in the outer layer (corresponding to the low milling flow rate) is significantly higher than the oil concentration obtained in medium and high flow rates. Schramm et al. [15] stated that instead of treating the entire bran layer as a homogenous material, fractionating the bran layer and measuring component concentrations could result in a high value material for processing because such bran material would contain a higher concentration of a component(s) of interest than the overall bran layer average, and that less bran would need to be processed to obtain those components of interest. These results show that the outer bran layer fraction of Jazzman results in a relatively oil rich fraction of $19.7 \%$; if milled at the industrial scale, bran collected from Jazzman after the first milling break would be used for oil extraction. 


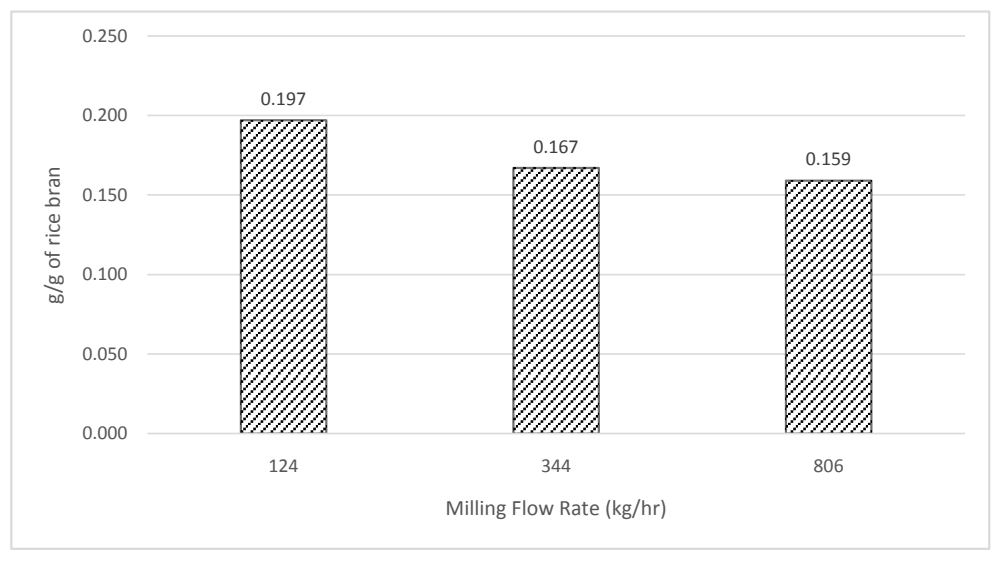

Figure 2. Rice bran oil concentration as a fuction of milling flow rate.

Schramm et al. [16] measured oil concentrations across the bran layer of a purple rice variety and found that oil concentration was highest (22\%) at the inner bran layer. Although such results were obtained at the laboratory scale, the researchers pooled fractions into an inner and outer bran layer, corresponding to the type of broad (vs. precise) control of bran fraction collection at the industrial scale. Using this approach, they found that the inner bran layer had 1.6 times as much oil as the outer bran layer. In comparing our results with those in published literature, we realize that as with milling, each rice variety must be analyzed individually to optimize performance and to determine the location of high-value components within the bran layer.

\section{Conclusions}

Jazzman presented as a high-yield, commercially viable milling aromatic rice variety. Yield and milling quality were comparable to two commercially successful non-aromatic varieties grown in the same area and to two long grain aromatic varieties grown in Bangladesh. Pilot scale milling of Jazzman showed that bran was removed easily from this variety and that rice milling at low flow rate with subsequent water polishing maximized yield, produced kernels of commercially acceptable quality, and produced rice bran with the highest percent oil that could be extracted for use in applications such as production of biodiesel. Pilot scale milling can be important to screen new rice varieties for their commercial viability and potential for value-added processing.

Future studies can test more rice varieties as a function of milling scale (laboratory, pilot, and/or industrial) to determine if models can be developed to accurately predict the milling yield and quality of a prospective rice variety based on laboratory or pilot scale milling data.

\section{Acknowledgements}

The authors gratefully acknowledge Steve Linscombe and the LSU AgCenter Rice Research Station for providing the rice milled for this study and the on-going collaboration that produced this research. LSU and the LSU AgCenter provided financial support for this research.

\section{References}

[1] Sha, X.Y., Linscombe, S.D., Jodari, F., Chu, Q.R., Groth, D.E., Blanche, D.E., Harrell, D.L., White, L.M., Oard, J.H., Chen, M.H., Theunissen, S.J. and Henry, B.J. (2011) Registration of "Jazzman" Aromatic Long-Grain Rice. Journal of Plant Registrations, 5, 304-308. http://dx.doi.org/10.3198/jpr2011.02.0081crc

[2] Linscombe, S. and Sha, X. (2009) Jazzman: A New Jasmine-Type Rice Variety. Louisiana Agriculture, 52, 13.

[3] Sha, X. (2008) Breeding for Improved Jasmine-Type Rice Lines. Rice Research Station News, 1-2.

[4] Linscombe, S., Sha, X., Bearb, K., Groth, D., White, L. and Dunand, R. (2006) Registration of "Cheniere" Rice. Crop Science, 46, 1814-1815. http://dx.doi.org/10.2135/cropsci2006.02-0118

[5] Hua, N., Bengtson, R., Schramm, R., Patel, T., Walker, T. and Lima, M. (2006) Optimization of Yield and Quality Parameters for the Cocodrie Rice Variety as a Function of Harvest Time. Applied Engineering in Agriculture, 22, 95-99. http://dx.doi.org/10.13031/2013.20175 
[6] Chen, H., Siebenmorgen, T. and Griffin, K. (1998) Quality Characteristics of Long-Grain Rice Milled in Two Commercial Systems. Cereal Chemistry, 75, 560-565. http://dx.doi.org/10.1094/CCHEM.1998.75.4.560

[7] Singh, R., Singh, U. and Khush, G. (2000) Aromatic Rice. Oxford \& IBH Publishing, New Delhi.

[8] International Rice Research Institute (2009) Physical Quality of Milled Rice. Rice Knowledge Bank. http://www.knowledgebank.irri.org/training/fact-sheets/postharvest-management/rice-quality-fact-sheet-category/item/ physical-quality-of-milled-rice-fact-sheet

[9] United States Department of Energy (2013) Replacing the Whole Barrel To Reduce U.S. Dependence on Oil. http://www.energy.gov/sites/prod/files/2014/04/f14/replacing_barrel_overview.pdf

[10] Rashid, U., Anwar, F., Ansari, T., Arif, M. and Ahmad, M. (2009) Optimization of Alkaline Transesterification of Rice Bran Oil for Biodiesel Production Using Response Surface Methodology. Journal Chemicak Technology and Biotechnology, 84, 1364-1370. http://dx.doi.org/10.1002/jctb.2191

[11] Srilatha, K., Sree, R., Prabhavathi Devi, B.L.A., Sai Prasad, P.S., Prasad, R.B.N. and Lingaiah, N. (2012) Preparation of Biodiesel from Rice Bran Fatty Acids Catalyzed by Heterogeneous Cesium-Exchanged 12-Tungstophosphoric Acids. Bioresource Technology, 116, 53-57. http://dx.doi.org/10.1016/j.biortech.2012.04.047

[12] Adachi, D., Koda, R., Hama, S., Yamada, R., Nakashima, K., Ogino, C. and Kondo, A. (2013) An Integrative Process Model of Enzymatic Biodiesel Production through Ethanol Fermentation of Brown Rice Followed by Lipase-Catalyzed Ethanolysis in a Water-Containing System. Enzyme \& Microbial Technology, 52, 118-122. http://dx.doi.org/10.1016/j.enzmictec.2012.11.005

[13] Liu, W., Yin, P., Zhang, J., Tang, Q. and Qu, R. (2014) Biodiesel Production from Esterification of Free Fatty Acid over PA/NaY Solid Catalyst. Energy Conversion \& Management, 101, 8283-8291. http://dx.doi.org/10.1016/j.enconman.2014.02.062

[14] Saunders, R.M. (1985) Rice Bran: Composition and Potential Food Sources. Food Review International, 1, 465-495. http://dx.doi.org/10.1080/87559128509540780

[15] Schramm, R., Abadie, A., Hua, N., Xu, Z. and Lima, M. (2007) Fractionation of the Rice Bran Layer and Quantification of Vitamin E, Oryzanol, Protein, and Rice Bran Saccharide. Journal of Biological Engineering, 1, 1-9. http://dx.doi.org/10.1186/1754-1611-1-9

[16] Schramm, R., Plater, M., Walker, N., Jang, S., Xu, J. and Lima, M. (2012) Laboratory-Scale Characterization of a Purple Rice Variety: Examination of Milling Quality and Determination of Anthocyanin and Oil Concentration across the Bran Layer. Transactions of the ASABE, 55, 1577-1582. http://dx.doi.org/10.13031/2013.42226

[17] Proctor, A., Jackson, V., Scott, M. and Clark, P. (1994) Rapid Equilibrium Extraction of Rice Bran Oil at Ambient Temperature. JAOCS, 71, 1295-1296. http://dx.doi.org/10.1007/BF02540555

[18] XLSTAT-Pro (2009) Statistical Software.

[19] Bautista, R. and Siebenmorgen, T. (2002) Evaluation of Laboratory Mills for Milling Small Sample of Rice. Applied Engineering in Agriculture, 18, 577-583. http://dx.doi.org/10.13031/2013.10145

[20] Islam, S., Ghani, A., Islam, S. and Rahman, A. (2003) Effect of Drying and Temperature on the Milling Quality of Long Grain Aromatic Paddy Processing in Bangladesh. Pakistan Journal of Biological Sciences, 6, 1675-1680. http://dx.doi.org/10.3923/pjbs.2003.1675.1680

[21] Sha, X. and Linscombe, S. (2011) Development of a Jasmine-Type Variety for the Southern United States. Louisiana Agriculture Magazine, 54, 6-8.

[22] Chen, H. and Siebenmorgen, T. (1997) Effect of Rice Kernel Thickness on Degree of Milling and Associated Optical Measurements. Cereal Chemistry, 74, 821-825. http://dx.doi.org/10.1094/CCHEM.1997.74.6.821

[23] Pan, Z., Thompson, J., Amaratunga, K., Anderson, T. and Zheng, X. (2005) Effect of Cooling Methods and Milling Procedures on the Appraisal of Rice Milling Quality. Transactions of the ASABE, 48, 1865-1871. http://dx.doi.org/10.13031/2013.19984

[24] Reid, J., Siebenmorgen, T. and Mauromoustakos, A. (1998) Factors Affecting the Slope of Head Rice Yield vs. Degree of Milling. Cereal Chemistry I, 75, 738-741. http://dx.doi.org/10.1094/CCHEM.1998.75.5.738 